\title{
VALIDAÇÃO DO ZONEAMENTO ECOLÓGICO DOESTADO DO PARANÁ PARA PRODUÇÃO DE SEMENTES DE SOJA ${ }^{1}$
}

\author{
NILTON PEREIRADACOSTA²,CEZAR DE MELLO MESQUITA ${ }^{2}$,JOSÉ DE BARROS FRANÇA-NETO ${ }^{2}$, ANTONINHO C. MAURINA $^{3}$, FRANCISCO \\ CARLOS KRZYZANOWSKI' ${ }^{2}$ MARIACRISTINAN. DE OLIVEIRA ${ }^{4}$, ADEMIRA. HENNING ${ }^{2}$
}

\begin{abstract}
RESUMO - Em determinadas regiões do Estado do Paraná, o baixo potencial de germinação, atribuído às condições climáticas desfavoráveis, durante o período de maturação da soja, é o principal fator de eliminação de lotes de sementes. Objetivando avaliar a dimensão do problema o estudo visou determinar as regiões mais aptas do Paraná para produção de sementes de soja de elevado padrão fisiológico. Para tal, foram coletadas 121 amostras de sementes da cultivar BR 16 (1996/97, 1997/98 e 1998/1999) e 119 amostras da cultivar BRS 133 (1999/2000, 2000/2001 e 2001/ 2002). Os parâmetros tomados por base para analisar a qualidade das sementes foram: germinação (\%), vigor (TZ 1-3), viabilidade (TZ 1-5), deterioração por umidade (TZ 6-8), dano mecânico (6-8) e lesões de percevejos (TZ 6-8). Para interpretação dos dados, o estado do Paraná foi dividido em três regiões ecológicas: $\mathrm{T} 1$, temperatura média do mês mais quente (Fevereiro) $>24^{\circ} \mathrm{C}$; $\mathrm{T} 2$, temperatura média entre 22 e $24^{\circ} \mathrm{C}$; T3, temperatura média $<22^{\circ} \mathrm{C}$. A região $\mathrm{T} 3$ que abrange os municípios de Ponta Grossa, Guarapuava, Pato Branco, Marilândia do Sul, Francisco Beltrão e parte de Cascavel, destacou-se, invariavelmente, por apresentar reduzidos índices de sementes com deterioração por umidade, com dano mecânico e com lesões de percevejos, resultando num melhor potencial de germinação, de vigor e de viabilidade. A validação do zoneamento acológico adiciona uma tecnologia capaz de identificar a região Sul do estado do Paraná, com melhores condições climátcas para produção de sementes de soja de qualidade.
\end{abstract}

Termos para indexação: Glycine max, vigor, germinação, dano mecânico, viabilidade.

\section{VALIDATION ECOLOGICAL ZONING OF THE STATE OF PARANAFOR SEED PRODUCTION CULTIVARS OF SOYBEAN}

\begin{abstract}
ABSCTRACT- This study was carried out to determine the ecological regions most suitable for soybean seed production in the State of Parana, Brazil. At harvest, 121 seed samples of the cultivars BR 16 and 119 samples of BRS 133 were collected from different regions in the state, from 1997 to 2002 . Growing season seed quality evaluations were: standard germination and the tetrazolium test for field deterioration, mechanical damage and stink bug attack. Three regions were previously defined based upon mean temperature (MT) in February;:T1 region, with $\mathrm{AT}>24^{\circ} \mathrm{C}$; T2, with AT between 22 and $24^{\circ} \mathrm{C}$; and $\mathrm{T} 3$, with $\mathrm{AT}<22^{\circ} \mathrm{C}$. The region $\mathrm{T} 3$ produced the best quality seeds followed by regions $\mathrm{T} 2$ and $\mathrm{T} 1$. Mechanical damage during harvest significantly reduced seed quality, especially in regions $\mathrm{T} 1$ and T2. In general, region T3 was the most favorable area for production with high quality seed. Other factors, such as mechanical damage and stink bugs, were responsible for lowering seed quality of two soybean cultivars produced in the State of Parana. Based on the climatic chart of the State of Parana and the results obtained in this trial we can infer that the validation of ecological zoning is a solid alternative for seed producers in the State of Parana to search for suitable areas in which high quality soybean seed production is possible.
\end{abstract}

Index terms: Glycine max, vigor, germination, mechanical damage, viability

\footnotetext{
${ }^{1}$ Submetido em 25/05/2004. Aceito para publicação em 05/10/2004. Manuscrito aprovado pelo Chefe Adjunto de Pesquisa e Desenvolvimento da Embrapa Soja, sob o n ${ }^{\circ} 21 / 2004$.

${ }^{2} \mathrm{Eng}^{\mathrm{o}} \mathrm{Agr}^{\mathrm{o}}$, PhD., pesquisador, Embrapa Soja, Cx. Postal 231, 86.001-970,
}

Londrina-PR. E-mail:nilton@enpso.embrapa.br.

${ }^{3}$ Eng $^{\mathrm{o}} \mathrm{Agr}^{\mathrm{o}}$, extensionista, Emater/PR, Cx. Postal 1662, 80035-270, CuritibaPR.

${ }^{4}$ Lic. em Matemática, Doutorada-pesquisadora, Embrapa Soja. 


\section{INTRODUÇÃO}

A obtenção de sementes de alta qualidade é bastante problemática na maioria das regiões produtoras de soja do Brasil, especificamente, naquelas situadas ao norte do paralelo $24^{\circ} \mathrm{C}$. Nessas localidades, as freqüentes oscilações climáticas afetam de modo substancial a qualidade da semente produzida. Para Dajoz (1981) o clima é condicionado pela pressão atmosférica e geralmente em altitude elevada o ar é mais rarefeito e o vapor d'água é menos abundante, propiciando a obtenção de sementes de melhor qualidade. Sabe-se que sementes de soja são bastante sensíveis a ambientes quentes e úmidos no período de maturação, levando a redução da qualidade do material produzido. Esse quadro é agravado, principalmente, se tais condições estiverem associadas a temperaturas superiores à $24^{\circ} \mathrm{C}$ (Costa et al., 1994).

Historicamente a literatura indica que a deterioração de sementes está intimamente ligada a mudanças citológicas, fisiológicas, bioquímicas e físicas que, eventualmente promovem a morte das sementes. Além das conseqüencias diretas na germinação, no vigor e na viabilidade, a deterioração por umidade pode resultar num maior índice de quebras, de danos mecânicos e de ruptura de tegumento, uma vez que, sementes deterioradas são vulneráveis aos impactos de natureza mecânica, proporcionando redução do padrão das qualidades físicas e fisiológicas das sementes (França-Neto \& Henning, 1984).

A semente de soja é altamente higroscópica, tendo seu grau de umidade condicionado pelo ambiente, aumentando ou reduzindo seu volume em função da maior ou menor intensidade de absorção de água. O processo de deterioração pode ocorrer em qualquer ponto, durante a fase de maturação, porém, segundo Mondragon \& Potts (1974), seus efeitos negativos serão mais acentuados quando o grau de umidade das sementes for inferior a $25 \%$. A respeito do tema, Costa et al. (1994), Viera et al. (1982), Tekrony et al. (1980), Carter \& Hartwig (1962) afirmam que baixas temperaturas favorecem a qualidade das sementes e que condições quentes e úmidas, com excesso de precipitação, poderão comprometer severamente a germinação e o vigor. França-Neto \& Henning (1984) afirmam que as sucessivas expansões e contrações do volume das sementes em função de condições de chuvas e temperatura no estádio de maturação, ocasionam a formação de rugas nos cotilédones, na região oposta ao hilo, cujas lesões bastante peculiares e nitidamente observadas através do teste de tetrazólio. Os autores ainda destacam que o cansaço físico dos tecidos, que pode resultar em ruptura no tegumento e nos tecidos embrionários, comprometendo o controle de permeabilidade das membranas aos níveis celulares e subcelulares. Organelas, como os mitocôndrios, são particularmente afetadas por tal processo, havendo menor produção de energia (ATP) necessária para a germinação. Tachibana et al. (1968) afirmam que a necrose cotiledonar da soja, caracterizada pelo desenvolvimento de tecido morto dos cotilédones das plântulas, não é uma doença infecciosa, mas, pode ser atribuída a deterioração das sementes no período da maturação à colheita. Essa mesma necrose foi induzida em condições de laboratório por meio da elevação da temperatura.

Associado a esses fatores, a ocorrência de danos mecânicos proporciona redução significativa de qualidade fisiológica. O sistema de trilha utilizado pela maioria das colhedoras é o responsável pelas ações simultâneas de impacto, compressão e atrito transmitidos às sementes/grãos, que são levadas a passar entre o cilindro de trilha e o côncavo durante a operação de colheita.

Como conseqüência dessa ação, normalmente agressiva, as sementes poderão ser fragmentadas, quebradas, trituradas e danificadas, em diferentes níveis de tamanhos. Segundo Skromme (1977), as colhedoras com sistema de trilha axial, apresentam maior capacidade de colheita e permitem a redução dos índices de danos mecânicos, em relação às colhedoras com sistema de trilha com alimentação tangencial. Todavia, os custos de aquisição das máquinas axiais ainda são elevados para a maioria dos produtores brasileiros. Andrews (1965) e Delouche (1967) confirmam que a danificação é causada por choques e/ou abrasões contra superfícies duras ou contra outras sementes, resultando em sementes quebradas, danificadas, fragmentadas e trincadas. Sementes com essas características dificultam as operações de beneficiamento e geralmente apresentam problemas da germinação e do vigor.

Outro fator que tem causado sérios prejuízos à qualidade das sementes de soja, é o que resulta das lesões de percevejos, principalmente, devido à colonização dos tecidos das sementes por Nematospora coryli Peglion, o qual provoca acentuada deterioração. O período crítico de incidência desse inseto, de acordo com Panizzi et al. (1979), está compreendido entre os estádios de desenvolvimento e de enchimento de vagens. Nessa fase, o controle da praga deve ser realizado quando forem encontrados dois percevejos por metro, em lavouras comerciais e um percevejo por metro em lavouras destinadas a produção de sementes. Os autores ainda observaram nesse estudo, que alta proporção de microrganismos estavam associados com sementes danificadas por Piezodorus guildinii, dentre estes, Fusarium sp., infectando mais de $30 \%$ de 
sementes lesionadas pelo referido percevejo.

Em outro estudo, Jensen \& Menson (1972) verificaram, em sementes de 17 variedades de soja, que a região da lesão de percevejo, talvez, seja mais importante do que o número de picadas desse inseto. Os autores acrescentam que uma lesão no eixo radícula-hipocótilo pode comprometer severamente o vigor, o que pode ser facilmente identificado através do método de tetrazólio.

O objetivo do presente estudo foi identificar as regiões produtoras de soja do Estado do Paraná, com condições climáticas mais favoráveis para produção de sementes de alta qualidade.

\section{MATERIAL E MÉTODOS}

O estudo foi conduzido em parceria com a Emater/PR, através de coleta de amostras de sementes de soja dos cultivares BR 16 (safras 1996/97, 1997/98 e 1998/99) e BRS 133 (1999/00, 2000/2001 e 2001/2002), em três regiões do Estado do Paraná, conforme dados contidos da Tabela 1. Deve-se enfatizar que a mudança de genótipos ocorreu em função do declínio da área plantada com a "BR 16", o que dificultou a continuidade de amostragem da referida cultivar. Porém, com o incremento da cultivar BRS 133, em termos da área, resolveu-se introduzi-la para dar continuidade ao estudo, pois, a mesma representa em torno de $30 \%$ de área semeada no Estado do Paraná (Roessing, 2002).

Classificação das regiões produtoras de soja do Estado do Paraná, baseada na temperatura

A metodologia utilizada para a interpretação dos dados obtidos, foi através da divisão das regiões produtoras em T1, T2 e T3. Levando-se em consideração o critério de clima com base nas Cartas Climáticas Básicas do Estado do Paraná (Fundação Instituto Agronômico do Paraná, 1978). Para tal foi usado o agrupamento das regiões mediante a temperatura do mês mais quente (fevereiro). Geralmente, nesse período, ocorre a maturação dos campos de sementes de soja. O estado foi dividido em T1-temperatura média maior que $24^{\circ} \mathrm{C}$; T2temperatura média entre $22^{\circ} \mathrm{C}$ e $24^{\circ} \mathrm{C}$; e T3-temperatura média menor que $22^{\circ} \mathrm{C}$ (Tabela 1 ).

\section{Amostragem de campo}

As amostras foram coletadas nas principais regiões produtoras de soja do Estado do Paraná. Foram amostradas aproximadamente $5 \mathrm{Kg}$, por técnicos da Emater/PR, do SNT de Ponta Grossa e Técnicos da Embrapa Soja. Logo após a coleta, as amostras foram enviadas ao laboratório de sementes
TABELA 1. Número de amostras de sementes coletadas dos cultivares BR 16 e BRS 133 de acordo com as regiões e safras avaliados. Embrapa Soja, Londrina, PR.

\begin{tabular}{llrrrc}
\hline \multirow{2}{*}{ Cultivar } & \multirow{2}{*}{ Safra } & \multicolumn{4}{c}{ N. $^{\mathbf{o}}$ de Amostras } \\
\cline { 3 - 6 } & & T1 & T2 & T3 & Total \\
\hline \multirow{3}{*}{ BR 16 } & $1997 / 98$ & 41 & 15 & 10 & 66 \\
& $1998 / 99$ & 12 & 10 & 6 & 28 \\
& $1999 / 00$ & 5 & 5 & 7 & 17 \\
\hline \multirow{3}{*}{ BRS 133 } & $1999 / 00$ & 21 & 5 & 7 & 33 \\
& $2000 / 01$ & 31 & 8 & 12 & 51 \\
& $2001 / 02$ & 21 & 4 & 10 & 35
\end{tabular}

T1(região norte do Paraná)-Rancho Alegre, Leópolis, Paranavaí, Sertaneja, Londrina, Peabiru, Uraí, Cambé, Sertanópolis,

T2 (região oeste do Paraná)-Medianeira, Santa Cecília do Pavão, Campo Mourão, Pitanga, São Jerônimo da Serra, Toledo, Cambará, Faxinal, Roncador, Mamborê, Tibagi, Ivaí, Ipiranga, Juranda, Corbélia, Arapongas, Assai e Cornélio Procópio.

T3 (região sul do Paraná)-Marilândia do Sul, Guarapuava, Ponta Grossa, Castro, Cascavel, Mariópolis, Teixeira Soares, Catanduvas e Pato Branco.

da Embrapa Soja, para a condução dos testes de germinação, tetrazólio e análise química.

\section{Teste de germinação}

O teste de germinação foi realizado com 200 sementes (quatro sub-amostras de 50 sementes), para cada cultivar. As sementes foram semeadas em rolos de papel germitest e colocadas em germinador com temperatura regulada em $25^{\circ} \mathrm{C}$, por cinco dias. A contagem das plântulas foi realizada ao quinto dia após a semeadura, segundo os critérios adotados em (Brasil, 1992). Com os dados de germinação, calculou-se a percentagem de plântulas normais, por amostra.

\section{Teste de tetrazólio}

Foram usadas 100 sementes por cultivar, sendo acondicionadas em papel germitest umedecido, com quantidade de água equivalente a 2,5 vezes o seu peso, durante 16 horas, em temperatura ambiente. Passado esse período, as sementes foram colocadas em copos de bequer, numa solução de concentração de $0,075 \%$ de 2,3,5-trifenil-cloreto-de-tetrazólio e em seguida, foram colocadas no escuro, em estufa, com temperatura variando entre $35^{\circ} \mathrm{C}$ a $40^{\circ} \mathrm{C}$, por três horas. Após a lavagem em água corrente, as sementes foram analisadas individualmente, verificando-se percentagem de vigor, de viabilidade, de deterioração por umidade, de danos mecânicos e de lesões de percevejos, conforme metodologia descrita por França-Neto et al. (1998), onde a qualidade é colocada em evidência e permitindo, dessa forma, uma interpretação rigorosa na caracterização dos níveis de viabilidade. A importância da causa da perda de qualidade (percevejo, 
deterioração por umidade e dano mecânico) é aquilatada pelo percentual de sementes que perderam sua viabilidade (classes 6 a 8), devido a um desses danos.

\section{Teores de proteína, óleo e respectiva acidez}

A determinação dos percentuais de proteína dos grãos das cultivares, foi realizada em triplicata. Os teores de óleo foram processadas em duplicata. A determinação dos porcentuais de ácidos graxos livres, foi feita em duplicata, segundo metodologia adotada por Pregnolatto \& Pregnolatto (1985).

\section{RESULTADOS E DISCUSSÃO}

A análise estatística dos resultados indicou que a germinação e o vigor de sementes dos cultivares BR 16 e BRS 133 apresentou melhor potencial de qualidade, quando oriundas da região T3 (sul) e comparando-se com as regiões T1 (norte) e T2 (oeste) do Paraná, conforme valores contidos nas (Tabelas 2 e 3). Também foi constatado que na região T3 (sul), ocorreram baixos índices de deterioração por umidade (TZ 6-8), levando à obtenção de um bom padrão de germinação e vigor das sementes de ambas as cultivares. Contudo, a região T2 (oeste) apresentou um comportamento intermediário para as duas cultivares em função da melhor germinação e do vigor; entretanto, a região T1 (norte) apresentou maior proporção de lotes com sementes deterioradas (Tabelas 2 e 3) afetando o desempenho fisiológico das sementes. Com base nesses resultados, pode-se inferir que a validação do Zoneamento Ecológico do Paraná, agregará informações fundamentais na caracterização de áreas para produção de sementes de soja de alta qualidade. Deve-se acrescentar que a proposta de divisão do estado do Paraná em áreas isotérmicas, como opção, na seleção de locais para produção de sementes com elevado padrão de qualidade, pode ser considerada uma alternativa mais científica, embora, os dados de precipitação pluvial e de temperatura não fossem coletadas pela razão óbvia de número de locais amostrados e pela amplitude da área abrangida a qual poderia ocorrer algum tipo de erro, o que certamente implicaria na interpretação dos resultados. Todavia, deve-se enfatizar que a região sul do Paraná é caracterizada por altitude elevada, onde geralmente há predomínio de temperatura mais amena no período de maturação das sementes das cultivares testadas; enquanto as regiões norte e oeste são caracterizadas por temperaturas mais elevadas no período de maturação, o que geralmente propícia variação da qualidade fisiológica da semente obtida (Costa et al.;1994; Fundação Instituto Agronômico do Estado do Paraná, 1978). Por sua vez, Dajoz (1981) comenta que o clima é condicionado pela pressão atmosférica e geralmente em altitude elevada o ar é mais rarefeito e o vapor d'água é menos abundante, propiciando à obtenção de sementes de melhor qualidade. Todavia, Costa et al. (1994), Vieira et al. (1982), Green et al. (1966), Mondragon et al (1974), Pereira et al. (1979) indicam claramente a influência marcante da temperatura como parâmetro determinante da qualidade da semente produzida. Contudo, Koostra \& Harrington (1969) e Shultz et al. (1962) comentam que a auto-oxidação dos lipídios é certamente, uma das causas do envelhecimento das sementes, que pode ser alterada com a elevação da temperatura. Os lipídios são constituintes das membranas celulares, que são as primeiras estruturas a manifestarem evidências do processo de deterioração, que geralmente ocasionam prejuízos irreversíveis a qualidade das sementes da maioria das regiões produtoras de soja do Brasil.

TABELA2. Percentuais de germinação, viabilidade, vigor e deterioração por umidade de sementes da cultivar BR 16, produzidos nas regiões (sul, oeste e norte do Paraná) nas safras 1997/1998, 1998/1999 e 1999/2000. Embrapa Soja, Londrina, PR, 2004.

\begin{tabular}{lcccc}
\hline \multirow{2}{*}{ Região/Safra } & \multicolumn{3}{c}{ Variáveis Analisadas } \\
\cline { 2 - 5 } & Germinação & Viabilidade & Vigor & Deterioração por Umidade \\
\hline T3 Paraná - sul/1997-1998 & $79,0 \mathrm{a}$ & $87,8 \mathrm{a}$ & $73,0 \mathrm{a}$ & $3,6 \mathrm{a}$ \\
T2 Paraná - oeste/1997-98 & $63,8 \mathrm{~b}$ & $70,4 \mathrm{~b}$ & $48,0 \mathrm{~b}$ & $15,8 \mathrm{a}$ \\
T1 Paraná - norte/1997-98 & $62,2 \mathrm{~b}$ & $74,6 \mathrm{~b}$ & $54,0 \mathrm{~b}$ & $18,5 \mathrm{~b}$ \\
\hline Média & 68,3 & 77,6 & 58,3 & 12,6 \\
\hline T3 Paraná - sul/1998-1999 & $82,5 \mathrm{a}$ & $89,0 \mathrm{a}$ & $71,0 \mathrm{a}$ & $4,9 \mathrm{~b}$ \\
T2 Paraná - oeste/1998-99 & $79,7 \mathrm{ab}$ & $81,0 \mathrm{~b}$ & $60,0 \mathrm{~b}$ & $\mathrm{ab}$ \\
T1 Paraná - norte/1998-99 & $73,0 \mathrm{~b}$ & $78,0 \mathrm{~b}$ & $53,0 \mathrm{~b}$ & $6,2 \mathrm{a}$ \\
\hline Média & 78,4 & 82,7 & 61,3 & 4,3 \\
\hline T3Paraná - sul/1999-2000 & $91,4 \mathrm{a}$ & $91,2 \mathrm{a}$ & $81,0 \mathrm{a}$ & $1,4 \mathrm{a}$ \\
T2 Paraná - oeste/1999-00 & $86,0 \mathrm{ab}$ & $86,5 \mathrm{a}$ & $72,5 \mathrm{ab}$ & $3,1 \mathrm{a}$ \\
T1 Paraná - norte/1999-00 & $82,6 \mathrm{~b}$ & $83,8 \mathrm{a}$ & $64,3 \mathrm{~b}$ & $7,1 \mathrm{a}$ \\
\hline Média & 86,7 & 87,2 & 72,6 & 3,9 \\
\hline
\end{tabular}

Médias seguidas pela mesma letra, na coluna, não diferem entre si, pelo teste de Duncan a 5\% de probabilidade. 
TABELA 3. Percentuais de germinação, viabilidade, vigor e deterioração por umidade de sementes da cultivar BRS 133, produzidos nas regiões (sul, oeste e norte do Paraná) nas safras 1999/2000, 2000/2001 e 2001/2002. Embrapa Soja, Londrina, PR, 2004.

\begin{tabular}{lcccc}
\hline \multirow{2}{*}{ Região/Safra } & \multicolumn{3}{c}{ Variáveis Analisadas } \\
\cline { 2 - 5 } & Germinação & Viabilidade & Vigor & Deterioração por Umidade \\
\hline T3 Paraná - sul/ 1999-2000 & $90,0 \mathrm{a}$ & $90,0 \mathrm{a}$ & $79,0 \mathrm{a}$ & $0,43 \mathrm{a}$ \\
T2 Paraná - oeste/1999-00 & $86,6 \mathrm{~b}$ & $72,7 \mathrm{~b}$ & $67,2 \mathrm{~b}$ & $8,75 \mathrm{a}$ \\
T1 Paraná - norte/1999-00 & $85,8 \mathrm{a}$ & $86,8 \mathrm{a}$ & $72,0 \mathrm{a}$ & $0,71 \mathrm{a}$ \\
\hline Média & 89,3 & 86,5 & 72,7 & 3,3 \\
\hline T3 Paraná - sul/ 2000-2001 & $84,4 \mathrm{a}$ & $88,7 \mathrm{a}$ & $75,4 \mathrm{a}$ & $1,2 \mathrm{a}$ \\
T2 Paraná - oeste/ 2000-01 & $71,7 \mathrm{~b}$ & $77,3 \mathrm{~b}$ & $56,0 \mathrm{~b}$ & $5,0 \mathrm{a}$ \\
T1 Paraná - norte/ 2000-01 & $70,4 \mathrm{~b}$ & $77,7 \mathrm{~b}$ & $55,0 \mathrm{~b}$ & $9,0 \mathrm{a}$ \\
\hline Média & 75,5 & 81,2 & 62,1 & 5,1 \\
\hline T3 Paraná - sul/ 2001-2002 & $90,2 \mathrm{a}$ & $87,3 \mathrm{a}$ & $75,5 \mathrm{a}$ & $0,85 \mathrm{a}$ \\
T2 Paraná - oeste/ 2001-02 & $74,0 \mathrm{~b}$ & $79,4 \mathrm{~b}$ & $61,0 \mathrm{~b}$ & $2,1 \mathrm{~b}$ \\
T1 Paraná - norte/ 2001-02 & $63,0 \mathrm{c}$ & $70,2 \mathrm{c}$ & $49,6 \mathrm{c}$ & $7,9 \mathrm{~b}$ \\
\hline Média & 75,7 & 79,0 & 62,0 & 3,6 \\
\hline
\end{tabular}

Médias seguidas pela mesma letra, na coluna, não diferem entre si, pelo teste de Duncan a $5 \%$ de probabilidade.

Ainda a respeito do assunto, Vieira et al. (1982), observaram através de um estudo de épocas de colheita, que chuvas de até $40 \mathrm{~mm}$ não proporcionaram quedas acentuadas de germinação de sementes de soja, pois, a temperatura manteve-se no intervalo de 15 a $25^{\circ} \mathrm{C}$ (mínimo-máxima). Já Tekrony et al. (1980) constatou que à temperatura de $22,2^{\circ} \mathrm{C}$, na ausência total de chuvas, o primeiro declínio no vigor ocorreu após a maturação de campo, porém, a $12,2^{\circ} \mathrm{C}$ a perda de vigor foi significativa apenas depois de 39 dias. Contudo, França-Neto \& Henning (1984) afirmam que as sucessivas expansões e contrações do volume das sementes em função de condições de chuvas e temperatura no estádio de maturação, ocasionam a formação de rugas nos cotilédones, na região oposta ao hilo, cujas lesões bastante peculiares e nitidamente observadas através do teste de tetrazólio. Os autores ainda destacam que o cansaço físico dos tecidos, que

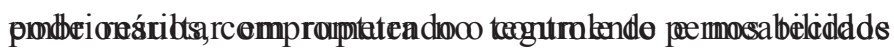
das membranas aos níveis celulares e sub-celular. Organelas, como os mitocôndrios, são particularmente afetadas por tal processo, havendo menor produção de energia (ATP) necessária para a germinação. Para Tachibana et al. (1968) a necrose cotiledonar da soja, caracterizada pelo desenvolvimento de tecido morto dos cotilédones das plântulas, não é uma doença infecciosa, mas, pode-se ser atribuída a deterioração das sementes no período da maturação à colheita. Essa mesma necrose foi induzida em condições de laboratório por meio da elevação da temperatura.

Com relação a danos mecânicos, ruptura de tegumento e quebra de sementes, os resultados mostram através da análise de variância índices acentuados de sementes danificadas mecanicamente para ambas as cultivares, sendo em maiores intensidades nas regiões norte (T1) e oeste (T2) e em menor proporção na região sul (T3) do Paraná, conforme (Tabelas 4 e 5). Ainda observou-se que sementes que apresentaram incidência de danos mecânicos até 5\% (TZ 6-8), não tiveram o comportamento fisiológico afetado; contudo, a partir de 6\% (TZ 6-8) ocorreu declínio acentuado do vigor, como era de se esperar. Esse quadro de variabilidade de qualidade física é preocupante e merece ser destacado com ênfase, pois, percentuais significados de lotes de sementes são descartados e comercializados com grãos em parte significativa de regiões produtoras de soja do Brasil. A respeito do tema, a literatura tem indicado que o manuseio constante da semente de soja, desde a colheita até o armazenamento, geralmente leva a minidanificações, cuja somatória final permite o declínio acentuado da qualidade da semente (Carvalho, 2001). Segundo esse autor, no caso da soja, por exemplo, em que o número de sementes por grama varia de 6 a 13, redução de um ponto no percentual de germinação, significa em uma tonelada, uma redução de 60.000 a 130.000 no número de sementes com capacidade de germinação.

A análise estatística dos resultados referentes a lesões de percevejos (Tabelas 4 e 5) não indicou problemas sérios de redução de qualidade fisiológica para sementes dos cultivares avaliados, à exceção das amostras da cultivar BR 16, proveniente do norte do Paraná, safra 1999/2000. Deve-se enfatizar que os índices obtidos ficaram abaixo de 5\% (TZ 68) não proporcionando injúria relevante a ponto de inviabilizar a germinação e o vigor das sementes. Dentro desse raciocínio, 
França-Neto et al. (1998) mencionam que amostras de sementes de soja com índices de lesões de percevejos entre $7 \%$ e 10\% (TZ 6-8) poderão ocorrer restrições do desempenho da qualidade fisiológica.

Por sua vez, os resultados da qualidade química, indicaram que ocorreram pequenas variações entre os teores de proteína e óleo para as cultivares avaliadas, nas três regiões amostradas (Tabela 6). Esses resultados estão de acordo com as observações averiguadas por Mandarino et al. (1996). Todavia, os índices de acidez não chegaram a comprometer a qualidade do óleo; apesar de, em alguns casos, ter ocorrido valor superior a $1 \%$, especialmente, com a cultivar BRS 133 na safra 2001/2002. Porém, nas demais safras agrícolas, constatou-se baixos valores de acidez do óleo (Tabela 6), não alterando o comportamento do óleo e de proteína.

TABELA 4. Percentuais de danos mecânicos, lesões de percevejos, sementes quebradas (bandinhas), ruptura de tegumento (teste de hipoclorito) de sementes da cultivar BRS 133, produzidos nas regiões (sul, oeste e norte do Paraná) nas safras 1999/ 2000, 2000/2001 e 2001/2002. Embrapa Soja, Londrina, PR, 2004.

\begin{tabular}{lcccc}
\hline & \multicolumn{4}{c}{ Variáveis Analisadas } \\
\cline { 2 - 5 } Região/Safra & Dano Mecânico & $\begin{array}{c}\text { Lesão por } \\
\text { Percevejos }\end{array}$ & $\begin{array}{c}\text { Sementes } \\
\text { Quebradas }\end{array}$ & Hipoclorito \\
\hline T3 Paraná - sul/ 1999-2000 & $6,0 \mathrm{a}$ & $1,0 \mathrm{a}$ & $6,2 \mathrm{a}$ & $9,2 \mathrm{a}$ \\
T2 Paraná - oeste/1999-00 & $8,8 \mathrm{a}$ & $3,2 \mathrm{a}$ & $8,9 \mathrm{a}$ & $12,6 \mathrm{a}$ \\
T1 Paraná - norte/1999-00 & $7,9 \mathrm{a}$ & $3,8 \mathrm{a}$ & $6,2 \mathrm{a}$ & $11,0 \mathrm{a}$ \\
\hline Média & 7,6 & 2,7 & 7,1 & 11,0 \\
\hline T3 Paraná - sul/ 2000-2001 & $5,7 \mathrm{a}$ & $2,5 \mathrm{a}$ & $8,0 \mathrm{a}$ & $18,5 \mathrm{a}$ \\
T2 Paraná - oeste/ 2000-01 & $11,7 \mathrm{~b}$ & $5,4 \mathrm{a}$ & $14,0 \mathrm{~b}$ & $25,5 \mathrm{~b}$ \\
T1 Paraná -norte/ 2000-01 & $6,0 \mathrm{~b}$ & $5,1 \mathrm{a}$ & $8,4 \mathrm{a}$ & $18,9 \mathrm{~b}$ \\
\hline Média & 7,8 & 4,3 & 10,1 & 21,0 \\
\hline T1 Paraná - sul/ 2001-2002 & $10,9 \mathrm{a}$ & $1,4 \mathrm{a}$ & $8,0 \mathrm{a}$ & $16,4 \mathrm{a}$ \\
T2 Paraná - oeste/ 2001-02 & $11,4 \mathrm{a}$ & $7,1 \mathrm{~b}$ & $10,0 \mathrm{a}$ & $20,0 \mathrm{a}$ \\
T3 Paraná- norte/ 2001-02 & $14,6 \mathrm{a}$ & $6,3 \mathrm{~b}$ & $10,0 \mathrm{a}$ & $22,0 \mathrm{a}$ \\
\hline Média & 12,3 & 4,9 & 9,3 & 19,5 \\
\hline
\end{tabular}

Médias seguidas pela mesma letra, na coluna, não diferem entre si, pelo teste de Duncan a $5 \%$ de probabilidade.

TABELA 5. Percentuais de danos mecânicos, de lesões de percevejos, de sementes quebradas (bandinhas), ruptura de tegumento (teste de hipoclorito) de sementes da cultivar BR 16, produzidos nas regiões (sul, oeste e norte do Paraná) nas safras 1997/1998, 1998/1999 e 1999/2000. Embrapa Soja, Londrina, PR,

\begin{tabular}{lcccc}
\hline \multirow{2}{*}{ Região/Safra } & \multicolumn{4}{c}{ Variáveis Analisadas } \\
\cline { 2 - 5 } & Dano Mecânico & Lesão por Percevejos & Sementes Quebradas & Hipoclorito \\
\hline T3 Paraná - sul/1997-1998 & $7,7 \mathrm{a}$ & $2,4 \mathrm{a}$ & $7,8 \mathrm{a}$ & $20,6 \mathrm{a}$ \\
T2 Paraná - oeste/1997-98 & $10,1 \mathrm{~b}$ & $4,4 \mathrm{~b}$ & $9,0 \mathrm{a}$ & $22,0 \mathrm{a}$ \\
T1 Paraná - norte/1997-98 & $11,5 \mathrm{~b}$ & $2,5 \mathrm{a}$ & $8,6 \mathrm{a}$ & $23,0 \mathrm{a}$ \\
\hline Média & 10,0 & 3,1 & 8,5 & 22,0 \\
\hline T3 Paraná - sul/1998-1999 & $7,5 \mathrm{a}$ & $2,6 \mathrm{a}$ & $6,4 \mathrm{a}$ & $18,3 \mathrm{a}$ \\
T2 Paraná - oeste/1998-99 & $11,4 \mathrm{~b}$ & $3,6 \mathrm{a}$ & $10,0 \mathrm{a}$ & $21,0 \mathrm{a}$ \\
T1 Paraná - norte/1998-99 & $10,8 \mathrm{~b}$ & $3,0 \mathrm{a}$ & $8,9 \mathrm{a}$ & $22,6 \mathrm{a}$ \\
\hline Média & 9,9 & 3,1 & 8,4 & 20,6 \\
\hline T3Paraná - sul/1999-2000 & $7,0 \mathrm{a}$ & $1,2 \mathrm{a}$ & $7,6 \mathrm{a}$ & $12,2 \mathrm{a}$ \\
T2 Paraná - oeste/1999-00 & $5,3 \mathrm{a}$ & $4,2 \mathrm{a}$ & $5,7 \mathrm{a}$ & $12,0 \mathrm{a}$ \\
T1 Paraná - norte/1999-00 & $5,2 \mathrm{a}$ & $6,7 \mathrm{a}$ & $6,2 \mathrm{a}$ & $14,9 \mathrm{a}$ \\
\hline Média & 5,8 & 4,0 & 6,5 & 13,0 \\
\hline
\end{tabular}

Médias seguidas pela mesma letra, na coluna, não diferem entre si, pelo teste de Duncan a $5 \%$ de probabilidade. 
TABELA 6. Resultados médios de análise química de grãos dos cultivares BR 16 e BRS 133, produzidas em diferentes localidades do Estado do Paraná, de

\begin{tabular}{|c|c|c|c|c|c|}
\hline \multirow{2}{*}{ Cultivar } & \multirow{2}{*}{ Safra } & \multirow{2}{*}{ Regiões } & \multicolumn{3}{|c|}{ Análise química (\%) } \\
\hline & & & Proteína & Oleo & Acidez \\
\hline \multirow{6}{*}{ BR 16} & \multirow{3}{*}{ 1998/99 } & T1 & 40,3 & 20,0 & 0,4 \\
\hline & & $\mathrm{T} 2$ & 38,6 & 19,6 & 0,5 \\
\hline & & T3 & 40,8 & 18,9 & 0,5 \\
\hline & \multirow{3}{*}{ 1999/00 } & T1 & 40,3 & 21,0 & 0,4 \\
\hline & & $\mathrm{T} 2$ & 38,6 & 22,1 & 0,5 \\
\hline & & $\mathrm{T} 3$ & 40,8 & 20,3 & 0,5 \\
\hline \multirow{9}{*}{ BRS 133} & \multirow{3}{*}{ 1999/00 } & T1 & 39,5 & 20,6 & 1,1 \\
\hline & & $\mathrm{T} 2$ & 39,6 & 20,7 & 0,8 \\
\hline & & T3 & 38,4 & 20,7 & 1,3 \\
\hline & \multirow{3}{*}{ 2000/01 } & T1 & 38,4 & 19,7 & 1,1 \\
\hline & & $\mathrm{T} 2$ & 37,9 & 20,4 & 0,8 \\
\hline & & T3 & 38,5 & 21,4 & 1,3 \\
\hline & \multirow{3}{*}{$2001 / 02$} & T1 & 37,5 & 20,6 & 1,6 \\
\hline & & $\mathrm{T} 2$ & 36,0 & 20,6 & 1,4 \\
\hline & & T3 & 38,2 & 19,9 & 1,7 \\
\hline
\end{tabular}

\section{CONCLUSÕES}

A validação do zoneamento ecológico adiciona uma tecnologia capaz de identificar a região Sul do Estado do Paraná, com melhores condições climáticas, para produção de sementes de soja de alta qualidade.

Deterioração por umidade e dano mecânico são, nessa ordem, os principais fatores que contribuem para redução da qualidade de sementes de soja enquanto as lesões de percevejos, não são tão expressivas.

\section{REFERÊNCIAS}

ANDREWS, C. Mechanical injury on seed. In: SHORT COURSE FOR SEEDSMEN, 1965, Mississippi. Proceedings... Mississippi: Seed Tecnology Laboratory, 1965. p.125-30.

BRASIL. Ministério da Agricultura e Reforma Agrária. Regras para análise de sementes. Brasília: SNDA/DNDV/CLAV, 1992. $365 \mathrm{p}$.

CARBONELL, S.A.M.; KRZYZANOWSKI, F.C.; MESQUITA, C.M. A device to impart impact on soybean seeds for screening genotypes for resistance to mechanical damage. Seed Science and Technology, Zürich, v.26, p.45-52, 1998.

CARTER, L. J.; HARTWIG, E. E. The management of soybean. Advances in Agronomy, New York, v.14, p.359-419, 1962.

CARVALHO, N. M. Injúria mecânica em sementes: um problema cada vez mais moderno. Seed News, Pelotas, v. 5, n.4, 2001.
COSTA, N. P.; OLIVEIRA, M.C.N.; HENNING, A.A.; KRZYZANOWSKI, F.C.; .MESQUITA, C.M.; TAVARES, L.C.V. Efeito da colheita mecânica sobre a qualidade da semente da soja. Revista Brasileira de Sementes, Brasília, v. 18, n. 2, p. 232-237, 1996.

COSTA, N.P.; PEREIRA, L.A.G.; FRANÇA-NETO, J. B.; HENNING, A.A.; KRZYZANOWSKI, F. C. Zoneamento ecológico do estado do Paraná para produção de sementes de cultivares precoces de soja. Revista Brasileira de Sementes, Brasília, v. 16, n. 1, p. 12-19, 1994.

DAJOZ, R. Ecologia geral. Petrópolis: Vozes, 1981. 47p.

DELOUCHE, J. Determinants of seed quality. In: SHORT COURSE FOR SEEDMEN, 1967, Mississippi. Proceedings... Mississippi: Seed Technology Laboratory, 1967.p.53-68.

FRANÇA-NETO, J. B.; HENNING, A.A. Qualidade fisiológica da semente. Londrina: EMBRAPA/CNPSo, 1984. p.5-24. Circular Técnica, 9.

FRANÇA-NETO, J. B.; KRZYZANOWSKI, F.C.; COSTA, N.P. O teste de tetrazólio em sementes de soja. Londrina: EMBRAPA/ CNPSo, 1998. 72p. Documentos, 116.

FRANÇA-NETO, J. B.; HENNING, A.A.; KRZYZANOWSKI, F.C. Seed production and technology for the tropics. In: EMBRAPA/ CNPSo. Tropical soybean: improvement and production. Roma: FAO, 1994. p. 217-240.

FUNDAÇÃO INSTITUTO AGRONÔMICO DO PARANÁ. Cartas climáticas básicas do estado do Paraná. Londrina: IAPAR, 1978. 41p.

GREEN, D.E.; CARANAH, L.E.; PINNELL, E.I. Effects on seed moisture content, field weathering, and combine cylinder speed on soybean seed quality. Crop Science, Madison, v.6, p. 7-10, 1966. 
JENSEN, R.L.; MENSON, L.D. Effect of sting-bug damaged soybean seed on germination, emergence and yield. Journal of Economic Entomology, College Park, v.55, p.261-264, 1972.

KOOSTRA, P. T.; HARRINGTON, J. F. Biochemical effects of age on membranal lipids of Cucumis sativum (L.) seed. Proceedings of the International Seed Testing Association, Copenhagen, v.34, n.2, p.329-340, 1969.

MANDARINO, J.M.G; CARRÃO-PANIZZI, M.C; ALMEIDA, L.A; OLIVEIRA, M.C.N. Chemical composition and amino acid profile of high protein Brasilian soybean. In: INTERNATIONAL SOYBEAN PROCESSING UTILIZATION CONFERENCE, 2., 1996, Bangkok. Proceedings... Kasetssart: Institute of Food Research and Product Development, 1996. p.102-108.

MESQUITA, C.M.; COSTA, N.P.; PEREIRA, J.E.; MAURINA, A.C.; ANDRADE, J.G.M. Colheita mecânica da soja: avaliação das perdas e da qualidade física do grão. Engenharia Agrícola, Jaboticabal, v. 18, n.3, p.44-53, 1999.

MONDRAGON,R.L.; POTTS.H.C. Field deterioration of soybean as affected by envionment. Proceedings of the Association of Official Seed Analysts, Beltsville, v.64, p. 63-71, 1974.

PANIZZI, A.R.; SMITH, J.G.; PEREIRA, L.A.G.; YAMASHITA, J. Efeitos dos danos de Piezodorus guildinii (Weestwood, 1837) no rendimento e qualidade da soja. In: SEMINARIO NACIONAL DE PESQUISA DE SOJA, 1., 1978, Londrina. Anais... Londrina: EMBRAPA/CNPSo, 1979. p.59-78.

PEREIRA, LA.G.; COSTA, N.P.; QUEIROZ, E.F; NEUMAIER, N.; TORRES, E. Efeito da época de semeadura sobre a qualidade de sementes de soja. Revista Brasileira de Sementes, Brasília, v.1, n.3, p.77-89, 1979 .

PREGNOLATTO, W.; PREGNOLATTO, N.P.(Coord.). Normas analíticas do Instituto Adolfo Lutz. 3.ed. v. 1. São Paulo: Instituto Adolfo Lutz, 1985. p.25-26,42-45.

ROESSING, A.C. Avaliação dos impactos econômicos e sociais da pesquisa da Embrapa Soja. Londrina: EMBRAPA CNPSO, 2002. 67p. Documentos, 189.

SCHULTZ, H.W.; DAY, E.A.; SINHOBER, R.O. Lipids on their oxidation. In: SYMPOSIUM ON FOOD. Westport: The Avid Publishing Company, 1962. p.442

SKROMME, L. H. Progress report on twin rotor combine concept of rotary threshing and separation. In: INTERNATIONAL GRAIN AND FORAGE HARVESTING CONFERENCE, 1., 1977, St. Joseph. Proceedings... St. Joseph: ASAE, 1977. p.188-191.

TACHIBANA, H.; METZER, R.B.; CRABE, D. F. Cotyledon necrosis in soybean. Plant Disease Reporter, Beltsville, v.52, n.6, p.459-62, 1968 .

TEKRONY, D. M.; EGLI,D.B.; PHILLIPS,A.D. Effects of field weathering on the viability and on vigor of soybean seed. Agronomy Journal, Madison, v. 72, n. 5, p.749-53, 1980.

VIERA, L.R.D.; SEDIYAMA, J.; SILVA, R.E.; SEDIYAMA,C.S.; THIEBAUT, J.T.I.; XIMENES, P. A. Estudo da qualidade fisiológica de semente de soja (Glicine max (L.) Merrill) cultivar UFV-1 em quinze épocas de colheita. In: SEMINÁRIO NACIONAL DE PESQUISA DE SOJA, 2., 1981. Brasília. Anais... Londrina: EMBRAPA/CNPSo, 1982. p.633-644. 